\begin{tabular}{ll|l}
\cline { 2 - 3 } & \multicolumn{3}{l}{ Intervent Neurol 2012;1:56-64 } \\
\cline { 2 - 3 } & $\begin{array}{l}\text { DOI: 10.1159/000346768 } \\
\text { Published online: February 12, } 2013\end{array}$ & $\begin{array}{l}\text { (C) 2013 S. Karger AG, Basel } \\
1664-9737 / 13 / 0012-0056 \$ 38.00 / 0 \\
\text { www.karger.com/ine }\end{array}$ \\
\hline
\end{tabular}

\title{
Review
}

\section{Early Endovascular Treatment of Subarachnoid Hemorrhage}

\author{
Jordi A. Matias-Guiu Carmen Serna-Candel \\ Department of Neurology, Hospital Clínico San Carlos, Madrid, Spain
}

\section{Key Words}

Early treatment - Endovascular coiling · Endovascular treatment - Subarachnoid hemorrhage . Timing

\begin{abstract}
Subarachnoid hemorrhage is an important cause of morbidity and mortality. Rebleeding is one of its major complications, which occurs mainly within the first $24 \mathrm{~h}$ and worsens the clinical outcome in a very dramatic way. It may be prevented by aneurysm treatment: surgical clipping or endovascular coiling. We review the evidence of and recent advances in endovascular treatment and timing of the intervention. Data supporting the benefit of early $(<72 \mathrm{~h})$ and ultra-early $(<24 \mathrm{~h})$ treatment is based on observational studies. An earlier approach may be relevant for the prevention of rebleeding and improvement of clinical outcome, but several disadvantages should be considered, such as an increased rate of periprocedural complications. Hence, a well-designed randomized controlled trial deems necessary to be able to define the optimal time of treatment. The possibility of treatment concomitant with the initial angiography should also be taken into account in this trial. This fact might represent a benefit favoring coiling over clipping in the prevention of rebleeding, and thus avoiding the inevitable delay necessary for the preparation for surgery.

Copyright (C) 2013 S. Karger AG, Basel
\end{abstract}

\section{Introduction}

Subarachnoid hemorrhage (SAH), with an approximate incidence of 10 cases per 100,000 inhabitants/year [1], is an important cause of morbidity and mortality. About $12-15 \%$ of patients die before hospital admission, and a further $30-45 \%$ die during the following days [2]. In addition, rates of sequelae are also high [3]. 
The two main and fearful complications that can occur after SAH are rebleeding and vasospasm, which are, therefore, the target that the available treatments and investigations pursue. Rebleeding is prevented by aneurysm obliteration, thus excluding it from the arterial circulation. Today, this can be achieved either by surgical clipping or endovascular coiling.

Several studies, especially the International Subarachnoid Aneurysmal Trial (ISAT) [4], support the efficacy and safety of endovascular treatment. However, whether the best approach is clipping or coiling, and in which specific settings, is still a matter open to discussion in current clinical practice and the related literature.

Furthermore, another historical controversy in the management of SAH has been the timing of aneurysm surgery. An early intervention reduces the risk of rebleeding, but surgical morbidity and vasospasm are more frequent in early than in late treatment.

The objective of this article is to review the current evidence regarding endovascular treatment and its early implementation. We will try to answer former questions regarding this relatively novel way of SAH management; for instance, we will discuss the optimal time period for coiling, if there is enough evidence to support early and ultra-early treatment, as well as the advantages and disadvantages of this approach.

\section{Rebleeding and Timing of Treatment}

Rebleeding worsens clinical outcome in a very dramatic way. This can be inferred from almost all studies, which have considered it as a major prognostic factor, with a mortality risk of up to $50-80 \%$ [5].

In historical data, this complication occurred in $15 \%$ of patients within the 1 st day, and in $40 \%$ of cases within the 1st month [6]. Nowadays, in spite of current treatments, rates probably range from 7 to 20\% [7-9], although these could be even higher due to the fact that in an important proportion of patients, diagnosis is overlooked because of previous hospital stays or initial worsening of the clinical situation [10]. Rebleeding is more frequent in the earlier phase after SAH, presumably because of the instability of both the clot and the fibrin net obliterating the ruptured aneurysm immediately after SAH. Rebleeding incidence peaks within the first $24 \mathrm{~h}$, clustering especially in the first 3-6 h, in which up to $50-75 \%$ of cases of rebleeding occur. From 13.6 to $37.1 \%$ of early rebleeding happens prior to hospital admission $[5,10]$. Therefore, overall, rebleeding occurs in the majority of cases during hospitalization, so improvement in the rates of this undesirable complication are of utmost importance.

Regarding the factors associated with a greater risk of rebleeding, different studies have found the clinical status on admission $[5,11]$ (measured by the Hunt and Hess scale), aneurysm size [5] and time to treatment as the main elements involved, together with sentinel headache [8], initial loss of consciousness and systolic blood pressure higher than $160 \mathrm{~mm} \mathrm{Hg} \mathrm{[10].}$ Other aspects, such as male gender [11], age [9], Fisher's scale or location of the aneurysm in the anterior communicating artery [11], have not been reported in a consistent way across the different studies.

\section{What Is the Evidence for Coiling?}

Endovascular treatment of aneurysms was introduced in 1990 based on the ability to occlude aneurysms by coil devices. Since the ISAT was published in 2002 [4], the endovascular approach has been performed increasingly. The ISAT was a multicenter and randomized clinical trial which compared surgical and endovascular treatments for SAH secondary to a 
Table 1. Main randomized studies concerning coiling and clipping in SAH

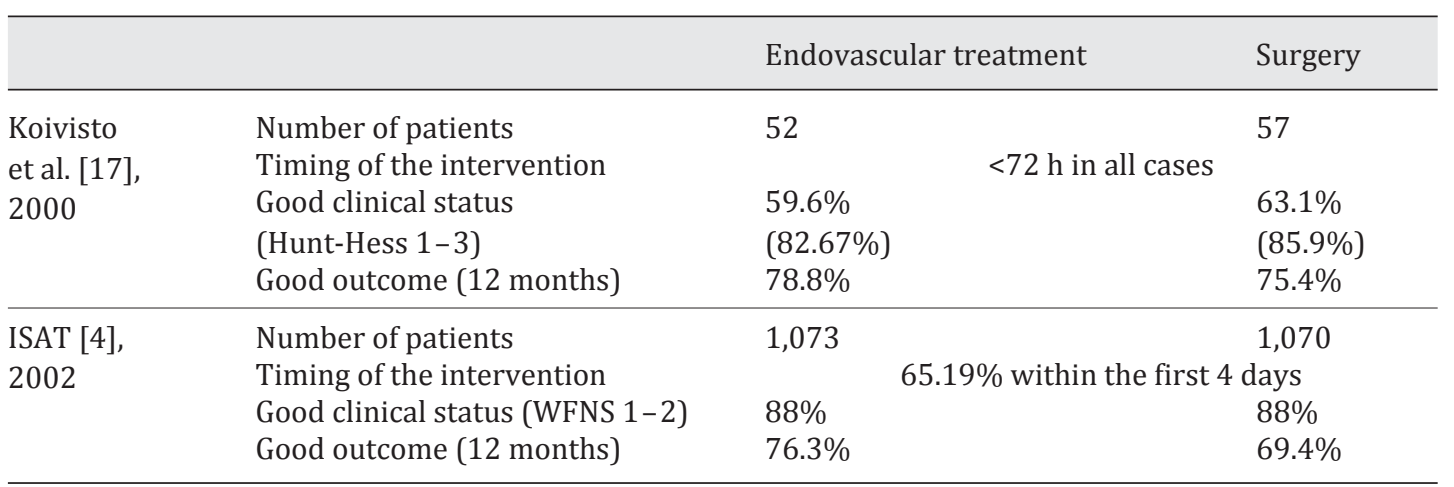

ruptured aneurysm. A total of 2,143 patients were included: 1,070 in the surgical group and 1,073 in the endovascular group. Patients were selected based on the principle of uncertainty, i.e. only the patients in which the best treatment (clip or coil) was unknown were included, which resulted in the exclusion of 7,416 patients before randomization. The parameters evaluated were functional outcome at 3 and 12 months, rebleeding and mortality. The main results were that $24 \%$ of the patients in the coiling group were dependent or dead at the 12-month follow-up compared with $31 \%$ of the patients who underwent clipping. Mortality at 1 year was $8.1 \%$ in the endovascular group versus $10.1 \%$ in the surgical group. There were no significant differences in rebleeding rates ( 2.7 vs. $2.6 \%$, respectively).

Only two additional randomized trials have been performed, and both of them were reviewed in a meta-analysis that included 2,272 patients, with only a few more than in the ISAT. The ISAT and the mentioned meta-analysis [12] concluded that in patients with good clinical status presenting with aneurysms amenable to endovascular and surgical treatment, coiling is associated with a better prognosis. The guidelines of clinical practice also support this approach [13]. Nonetheless, there is still a debate about the ISAT results, especially regarding their applicability in clinical practice, due to the fact that in this trial $88 \%$ of patients had a good clinical status (WFNS grades 1-2 of the World Federation of Neurological Societies) and in $92 \%$ of cases the aneurysm was less than $10 \mathrm{~mm}$ in size. Another criticism to coiling was the higher percentage of late retreatments (17.4 vs. 3.8\%) during follow-up [14]. However, this did not affect the overall outcome, which remained favorable towards the endovascular group 7 years later [15].

Recently, a subanalysis concerning the timing of the intervention in the ISAT population has been reported [16]. Here, $42.30 \%$ of patients were treated within the first 2 days, $22.88 \%$ in days $3-4,22.50 \%$ in days 5-10 and $12.30 \% 10$ days after the bleeding. Outcome and risk of delayed cerebral ischemia were similar in surgical and endovascular treatment groups (in each time period), although the risk of delayed ischemia was higher in the coiling group between days 5 and 10. A better outcome was achieved, again in both treatment groups, if the treatment was applied earlier, although several biases could be involved because the patients were not randomized according to the time of the intervention.

The former studies [4,17], which are summarized in table 1, support the use of endovascular coiling. This treatment is effective in the prevention of rebleeding, improves clinical outcome and, at least in a group of patients, seems to be superior to surgical treatment. In these studies, treatment was performed mostly within the first 3 days. However, their designs do not allow to draw definitive conclusions about timing of treatment. 
Table 2. Advantages and disadvantages of early treatment

\begin{tabular}{ll}
\hline Advantages & Disadvantages \\
\hline - Avoids rebleeding & - Suboptimal conditions of the intervention and more \\
- Allows a more aggressive management of & periprocedural complications \\
vasospasm and hydrocephalus & - Greater risk of vasospasm and infarction \\
& (especially from day 3 on) \\
\hline
\end{tabular}

\section{Advantages and Disadvantages of Early Treatment}

Since the 1980s, the optimal timing of surgery has been a matter of debate. Three intervention periods have been defined: early ( $<72 \mathrm{~h}$ from the hemorrhage), intermediate (3-10 days) and late ( $>10$ days) interventions, and many observational studies have been published with different results. The International Cooperative Study on the Timing of Aneurysm Surgery, a randomized trial, included 3,521 patients during the years 1980-1983 [18]. Outcome was worse if surgery was performed in the intermediate period, but there were no differences in outcome between early and late interventions. The benefit obtained in the prevention of rebleeding was probably lost by a higher surgical risk in the early period. However, a subanalysis of this study [19], other subsequent studies and a meta-analysis [20] supported early treatment; this was additionally favored because of the fact that neurocritical care was improved and the risks of early treatment were therefore reduced. In fact, nowadays, early treatment has been ascribed a class I/level B of evidence in the most recent guidelines [13].

Regarding the timing of endovascular treatment, studies that have randomized patients to different treatment times have not been published to date. Thus, the data available are exclusively from observational studies.

Theoretically, there are some advantages that favor early treatment. Firstly, it is associated with a lower incidence of rebleeding and, therefore, should be linked to a better outcome. Moreover, a secured aneurysm would allow the application of aggressive treatment against several complications, such as vasospasm with 'triple $\mathrm{H}^{\prime}$ therapy and hydrocephalus with external ventricular drainage (although this latter procedure has not been clearly associated with a higher risk of rebleeding) [9].

However, some disadvantages should also be mentioned (table 2). The strategy to treat as soon as possible may be associated with treatments performed in suboptimal conditions, such as less-experienced personnel and fatigue [21], increasing the possibility of periprocedural complications, but definitive confirmation is missing [22]; consistent data are lacking, and this circumstance may depend on the organization of the assistance in each clinical setting. Another point to consider is the risk of vasospasm and ischemic injuries in the acute and intermediate phases. There are several studies (some of them contradictory and none of them randomized) that evaluated the incidence of vasospasm and delayed ischemic lesions [23] in patients who underwent endovascular and surgical treatments and, additionally, a meta-analysis reviewed this issue [24]. This latter report concluded that there were no differences in the incidence of vasospasm with respect to the elected procedure, either coiling or clipping, although a trend towards higher rates of vasospasm were observed with clipping [relative risk 1.2 (0.99-1.48)]. Considering the risk of vasospasm in surgical and endovascular treatment equivalents, the probability to induce or worsen this complication by treating the aneurysm would be maximal at 5-10 days. This is in agreement with the study by Baltsavias et al. [25] and the ISAT [4]. In fact, in the ISAT, endovascular treatment is associated 
Table 3. Main studies about timing of coiling

\begin{tabular}{|c|c|c|c|c|c|c|}
\hline & $\begin{array}{l}\text { Patients } \\
\mathrm{n}\end{array}$ & Treatment & $\begin{array}{l}\text { Timing } \\
\text { days }\end{array}$ & $\begin{array}{l}\text { Good } \\
\text { outcome }\end{array}$ & $\begin{array}{l}\text { Significance } \\
\text { p value }\end{array}$ & $\begin{array}{l}\text { Vasospasm or } \\
\text { delayed } \\
\text { cerebral } \\
\text { ischemia }\end{array}$ \\
\hline $\begin{array}{l}\text { Phillips et al. } \\
\text { [26], } 2011\end{array}$ & 168 & Coiling & $\begin{array}{l}\leq 1 \\
>1\end{array}$ & $\begin{array}{l}96 \% \\
83 \%\end{array}$ & 0.001 & $\mathrm{NE}$ \\
\hline $\begin{array}{l}\text { Wong et al. } \\
\text { [28], } 2012\end{array}$ & 276 & $\begin{array}{l}\text { Coiling and } \\
\text { clipping }\end{array}$ & $\begin{array}{l}\leq 1 \\
1-2\end{array}$ & $\begin{array}{l}63.5 \% \\
59.3 \%\end{array}$ & NS & $\mathrm{NE}$ \\
\hline $\begin{array}{l}\text { Gu et al. [27], } \\
2012\end{array}$ & $\begin{array}{l}96 \\
(\geq 70 \text { years })\end{array}$ & Coiling & $\begin{array}{l}\leq 1 \\
>1\end{array}$ & $\begin{array}{l}87.5 \% \\
70 \%\end{array}$ & 0.034 & NE \\
\hline $\begin{array}{l}\text { Dorhout Meess } \\
\text { et al. [16], } 2012 \\
\text { (ISAT) }\end{array}$ & 1,084 & Coiling & $\begin{aligned} \leq & 2 \\
& 3-4 \\
& 5-10 \\
> & 10\end{aligned}$ & $\begin{array}{l}76 \% \\
74 \% \\
76 \% \\
64 \%\end{array}$ & - & $\begin{array}{l}21 \% \\
22 \% \\
29 \% \\
20 \%\end{array}$ \\
\hline $\begin{array}{l}\text { Baltsavias et al. } \\
{[25], 2000}\end{array}$ & 327 & Coiling & $\begin{array}{l}0-2(107) \\
3-10(125) \\
11-30(95)\end{array}$ & $\begin{array}{l}81 \% \\
84 \% \\
80 \%\end{array}$ & NS & $\begin{array}{l}21 \% \\
32 \% \\
39 \%\end{array}$ \\
\hline
\end{tabular}

Good outcome, which was determined at 6 months (except for ISAT: 2 months), is defined as modified Rankin scale 0-2, except for the study by Baltsavias et al. [25], where good outcome is defined as modified Glasgow Outcome Score 1-2 (equivalent to Glasgow Outcome Scale 4-5). NS = Nonsignificant; NE = not evaluated.

with significantly more vasospasm than surgical treatment 5-10 days after the hemorrhage. Manipulating cerebral parenchyma, which is edematous in the acute phase, can entail a greater risk of injury. This effect is usually prevented when coiling is performed, as it avoids contact with the cerebral parenchyma, although it does not remove the hemorrhage. Whereas surgical removal of part of the hemorrhage could decrease the risk of vasospasm as well as the risk of delayed ischemic injury, the intra-arterial access itself and treatment might nevertheless play a role in vasospasm and induce the formation of intravascular thrombi due to the manipulation of the artery itself.

However, due to the dismal prognosis associated with rebleeding and the possibility to treat the vasospasm in a more energetic way, including both medical and endovascular procedures, early treatment of ruptured aneurysms has been associated with a better outcome. This fact has been supported by previous studies on clipping and evaluated by some observational studies, which are summarized in table 3 . However, how early should this approach be performed? Most centers try to treat as early as possible, i.e. within the first $72 \mathrm{~h}$, according to current guidelines. However, in recent years, the conception of 'ultra-early' treatment has emerged, i.e. to secure the aneurysm within the first $24 \mathrm{~h}$, which is the period when most of the cases of rebleeding occur. Phillips et al. [26] analyzed the outcome of 459 consecutive patients admitted to a single center in the last 11 years; they compared patients treated within the first $24 \mathrm{~h}$ with those treated afterwards, mostly between days 1 and 3 . At the end, 168 patients underwent coiling and 291 clipping. In the endovascular group, $96 \%$ of the patients in the ultra-early coiled group were independent at 6 months, versus $83 \%$ in the group of patients treated with coiling $24 \mathrm{~h}$ after the onset of symptoms, even though patients 
Fig. 1. Proposed algorithm for timing of treatment in aneurysmal SAH.

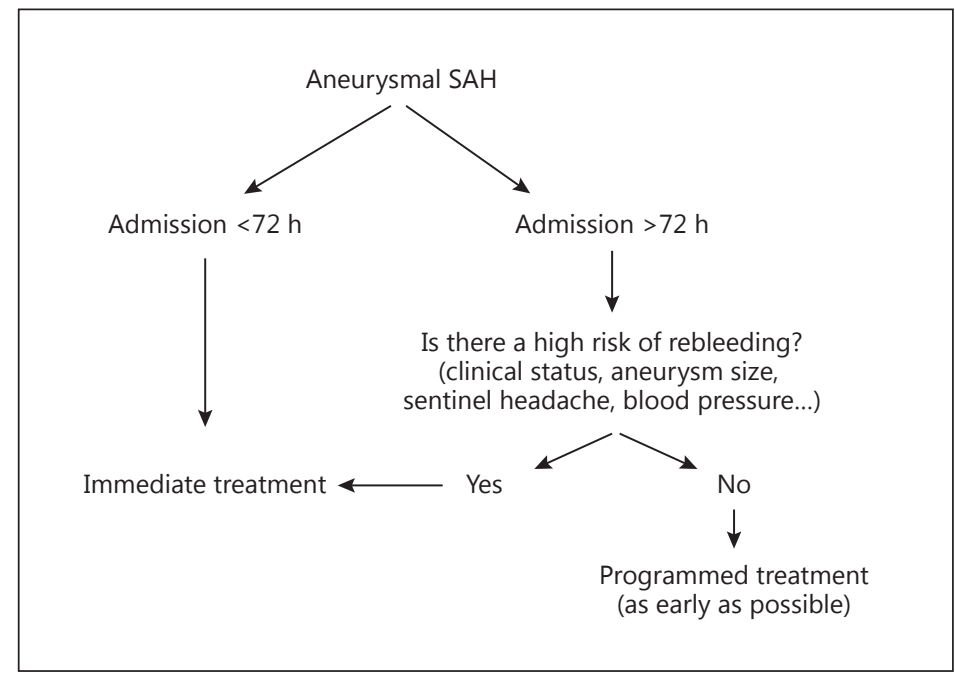

in the ultra-early group had a poorer clinical status and a higher Fisher grade. This benefit was more obvious in the endovascular group than in the surgical group. Another study was performed by Gu et al. [27] in the elderly, obtaining also a better outcome in patients undergoing coiling during the 1 st day.

Recently, Wong et al. [28] performed a post hoc analysis of the IMASH (Intravenous Magnesium Sulfate after Aneurysmal Subarachnoid Hemorrhage) trial. A total of 276 patients were treated, 148 within the first $24 \mathrm{~h}$ and 128 between 24 and $48 \mathrm{~h} ; 51 \%$ of the patients were treated by coiling in the ultra-early group, and $41 \%$ in the second group. After adjustment for age and clinical status, an association between an ultra-early approach and a good outcome was found. The better outcome was found in the cognitive but not in the physical state, especially in the group with poor neurological conditions. This difference between patients with good and poor clinical condition may be explained by the difference in rebleeding rates in ultra-early versus delayed groups ( 12 vs. $22 \%$ in patients in poor conditions, and $2.3 \mathrm{vs.} 1.1 \%$ in those in good clinical status).

As mentioned above, randomized data regarding timing of treatment are lacking. This means that several biases are possible when interpreting the previous studies. Firstly, they have been performed in tertiary centers, and, consequently, patients transferred from other centers may present with a poorer clinical status and may arrive later. This worse neurological status may delay the intervention. Also, patients who died prematurely may be excluded from the analysis. Moreover, the period of study is often long, and the exact time and period of treatment for each patient in each year is not specified. This may imply that patients from recent years could have been treated at earlier times, i.e. in the ultra-early period, whilst those who underwent the procedure 10 years ago would have been treated later on. So in the end, it would be as if historical controls were used instead of a proper case-control study, leading to its corresponding bias.

In spite of these limitations, the available data seem to confirm the safety and effectiveness of endovascular treatment in all time periods. We propose an algorithm of treatment including the variable time (fig. 1). Patients admitted within the first $72 \mathrm{~h}$ from hemorrhage development should be treated immediately, if possible, due to the high risk of rebleeding. On the other hand, patients admitted after $72 \mathrm{~h}$ may be treated as soon as possible considering the risk of rebleeding, with the purpose to achieve optimal conditions during the intervention, but a treatment delay after day 10 does not seem to be justified [16, 29]. 


\section{Concluding Remarks}

During the past years, a significant reduction in SAH morbidity and mortality has been achieved [30]. This may probably be due to early securing and stabilization of the aneurysm, as well as considerable improvement in the setting of neurological critical care. Nevertheless, the number of patients treated in the period considered early is still low [31]. Rebleeding rates remain high, especially during the first $6 \mathrm{~h}$, even in patients who received early treatment [10].

It seems reasonable, therefore, to suggest that an even earlier treatment of the aneurysm would result in a better prognosis. Following this idea, there have been several observational studies that have hypothesized benefits of ultra-early approaches. However, this would involve other complications, such as a greater risk of periprocedural unfavorable events, an increased need for retreatment and an increase in the number of patients transferred to different hospitals. Hence, a well-designed randomized controlled trial deems necessary to be able to define the optimal time of treatment, before 24 versus 24-72 $\mathrm{h}$. Elaborating clinical trials using these two time periods as the variables to evaluate would probably be exempt from ethical controversies, because of their overall conception of early treatment, as they are both within the first $72 \mathrm{~h}$. Endovascular treatment may be performed at the same time as the initial angiography, a fact that may be considered an important and practical advantage. However, on the other hand, this may lead to a longer overall duration of the procedure, which may be associated with a greater risk of subsequent complications, such as thrombus formation and vasospasm. Therefore, this issue should also be taken into account, and two subgroups of patients should be distinguished: those treated during the diagnostic arteriography itself and those treated in a second phase. Similarly, variables such as duration of the procedure, and location and complexity of the aneurysm should also be pointed out.

If we turn now to those patients with a poor or very poor clinical condition (WFNS grades 4-5 and Hunt and Hess grades 4-5), there is very little evidence to support the treatment [32]. Because these patients have a greater risk of rebleeding and other complications, an ultraearly approach would, presumably, be of benefit. However, because of the particular clinical conditions of this specific group, combined with the fact that they usually need other complementary treatments such as decompressive craniectomy or hematoma evacuation, an independent randomized clinical trial would be warranted and preferable.

In conclusion, there are sufficient data supporting the benefit of the early endovascular approach to $\mathrm{SAH}$, although evidence is not based on randomized clinical trials. The timing of the procedure has important prognostic implications, and early treatment may be associated with lower morbidity and mortality, especially due to the prevention of rebleeding. Additionally, if the benefit of the ultra-early approach is established, endovascular treatment might again be favored, because it can be carried out concomitant with the initial angiography, as previously mentioned. This would avoid the required delay for preparation for surgery, a time that deems relevant and significant for the prevention of rebleeding and the improvement of overall prognosis.

\section{Disclosure Statement}

The authors declare that there are no conflicts of interest. 


\section{References}

1 De Rooij NK, Linn FH, van der Plas JA, Algra A, Rinkel GJ: Incidence of subarachnoid haemorrhage: a systematic review with emphasis on region, age, gender and time trends. J Neurol Neurosurg Psychiatry 2007;78:13651372.

2 Nieuwkamp DJ, Setz LE, Algra A, Linn FH, de Rooij NK, Rinkel GJ: Changes in case fatality of aneurysmal subarachnoid haemorrhage over time, according to age, sex, and region: a meta-analysis. Lancet Neurol 2009; 8:635-642.

3 Ferro JM, Canhao P, Peralta R: Update on subarachnoid hemorrhage. J Neurol 2008;255:465-479.

- 4 International Subarachnoid Aneurysm Trial (ISAT) Collaborative Group: International Subarachnoid Aneurysm Trial (ISAT) of neurosurgical clipping versus endovascular coiling in 2,143 patients with ruptured intracranial aneurysms: a randomised trial. Lancet 2002;360:1267-1274.

5 Naidech AM, Janjua N, Kreiter KT, Ostapkovich ND, Fitzsimmons BF, Parra A, Commichau C, Connolly S, Mayer SA: Predictors and impact of aneurysm rebleeding after subarachnoid hemorrhage. Arch Neurol 2005;62: 410-416.

6 Javadpour M, Silver N: Subarachnoid haemorrhage (spontaneous aneurysmal). Clin Evid (Online) 2009;2009: 1213.

7 Hillman J, Fridriksson S, Nilsson O, Yu Z, Saveland H, Jakobsson KE: Immediate administration of tranexamic acid and reduced incidence of early rebleeding after aneurysmal subarachnoid hemorrhage: a prospective randomized study. J Neurosurg 2002;97:771-778.

8 Beck J, Raabe A, Szelenyi A, Berkefeld J, Gerlach R, Setzer M, Seifert V: Sentinel headache and the risk of rebleeding after aneurysmal subarachnoid hemorrhage. Stroke 2006;37:2733-2737.

- 9 Guo LM, Zhou HY, Xu JW, Wang Y, Qiu YM, Jiang JY: Risk factors related to aneurysmal rebleeding. World Neurosurg 2011;76:292-298.

10 Ohkuma H, Tsurutani H, Suzuki S: Incidence and significance of early aneurysmal rebleeding before neurosurgical or neurological management. Stroke 2011;32:1176-1180.

$\checkmark 11$ Cha KC, Kim JH, Kang HI, Moon BG, Lee SJ, Kim JS: Aneurysmal rebleeding: factors associated with clinical outcome in the rebleeding patients. J Korean Neurosurg Soc 2010;47:119-123.

12 Van der Schaaf I, Algra A, Wermer M, Monyneux A, Clarke M, van Gijn J, Rinkel G: Endovascular coiling versus neurosurgical clipping for patients with aneurysmal subarachnoid haemorrhage. Cochrane Database Syst Rev 2005;19:CD003085.

13 Sander Connolly ES Jr, Rabinstein AA, Carhuapoma R, Derdeyn CP, Dion J, Higashida RT, Hoh BL, Kirkness CJ, Naidech AM, Ogilvy CS, Patel AB, Thompson G, Vespa P: Guidelines for the management of aneurysmal subarachnoid hemorrhage: a guideline for healthcare professionals from the American Heart Association/ American Stroke Association. Stroke 2012;43:1711-1737.

14 Campi A, Ramzi N, Molyneux AJ, Summers PE, Kerr RSC, Sneade M, Yarnold JA, Rischmiller J, Byrne JV: Retreatment of ruptured cerebral aneurysm in patients randomized by coiling or clipping in the International Subarachnoid Aneurysm Trial (ISAT). Stroke 2007;38:1538-1544.

15 Molyneux AJ, Kerr RSC, Yu LM, Clarke M, Sneade M, Yarnold JA, Sandercock P, International Subarachnoid Aneurysm Trial (ISAT) Collaborative Group: International Subarachnoid Aneurysm Trial (ISAT) of neurosurgical clipping versus endovascular coiling in 2143 patients with ruptured intracranial aneurysms: arandomised comparison of effects on survival, dependency, seizures, rebleeding, subgroups and aneurysm occlusion. Lancet 2005;366:809-817.

-16 Dorhout Mees SM, Molyneux AJ, Kerr RS, Algra A, Rinkel GJE: Timing of aneurysmal treatment after subarachnoid hemorrhage: relationship with delayed cerebral ischemia and poor outcome. Stroke 2012;43: 2126-2129.

17 Koivisto T, Vanninen R, Hurskainen H, Saari T, Hernesniemi J, Vapalahti M: Outcomes of early endovascular versus surgical treatment of ruptured cerebral aneurysms: a prospective randomized study. Stroke 2000;32: 2369-2377.

18 Kassell NF, Torner JC, Jane JA, Haley EC Jr, Adams HP: The International Cooperative Study on the Timing of Aneurysm Surgery. Part 2: surgical results. J Neurosurg 1990;73:37-47.

19 Haley EC Jr, Kassell NF, Torner JC: The International Cooperative Study on the Timing of Aneurysm Surgery. The North American experience. Stroke 1992;23:205-214.

20 De Gans K, Nieuwkamp DJ, Rinkel GJE, Algra A: Timing of aneurysm surgery in subarachnoid hemorrhage: a systematic review of the literature. Neurosurgery 2002;50:336-340.

-21 Gooderham PA, Steinberg GK: Reflections on the benefits and pitfalls of ultra-early aneurysm treatment after subarachnoid hemorrhage. World Neurosurg 2011;77:261-262.

-22 Crowley RW, Yeoh HK, Stukenborg GJ, Ionescu AA, Kassell NF, Dumont AS: Influence of weekend versus weekday hospital admission on mortality following subarachnoid hemorrhage. Clinical article. J Neurosurg 2009;111:60-66.

23 Muñoz-Guillén NM, León-López R, Túnez-Fiñana I, Cano-Sánchez A: From vasospasm to the early brain injury: new frontiers in the investigation of subarachnoid haemorrhage research. Neurologia 2012, DOI: $\underline{10.1016 / \text { j.nrl.2011.10.015. }}$ 
24 De Oliveira JG, Beck J, Ulrich C, Rathert J, Raabe A, Seifert V: Comparison between clipping and coiling on the incidence of cerebral vasospasm after aneurysmal subarachnoid hemorrhage: a systematic review and metaanalysis. Neurosurg Rev 2007;30:22-32.

25 Baltsavias GS, Byrne JV, Halsey J, Coley SC, Sohn MJ, Molyneux AJ: Effects of timing of coil embolization after aneurysmal subarachnoid hemorrhage on procedural morbidity and outcomes. Neurosurgery 2000;47:13201331.

-26 Phillips TJ, Dowling RJ, Yan B, Laidlaw JD, Mitchell PJ: Does treatment of ruptured intracranial aneurysms within $24 \mathrm{~h}$ improve clinical outcome? Stroke 2011;42:1936-1945.

-27 Gu DQ, Zhang Z, Luo B, Long XA, Duan CZ: Impact of ultra-early coiling on clinical outcome after aneurysmal subarachnoid hemorrhage in elderly patients. Acad Radiol 2012;19:3-7.

-28 Wong GK, Boet R, Ng SC, Chan M, Gin T, Zee B, Poon WS: Ultra-early (within 24 hours) aneurysm treatment after subarachnoid hemorrhage. World Neurosurg 2012;77:311-315.

29 Lawson MF, Chi YY, Velat GJ, Mocco JD, Hoh BL: Timing of aneurysm surgery: the International Cooperative Study revisited in the era of endovascular coiling. J Neurointervent Surg 2010;2:131-134.

30 Rosen DS, Macdonald RL: Grading of subarachnoid hemorrhage: modification of the World Federation of Neurosurgical Societies scale on the basis of data for a large series of patients. Neurosurgery 2004;54:566575.

-31 Lamb JN, Crocker M, Tait MJ, Anthony Bell B, Papadopoulos MC: Delays in treating patients with good grade subarachnoid hemorrhage in London. Br J Neurosurg 2011;25:243-248.

32 Van Loon J, Waerzeggers Y, Wilms G, van Calenbergh F, Goffin J, Plets C: Early endovascular treatment of ruptured cerebral aneurysms in patients in very poor neurological condition. Neurosurgery 2002;50:457465. 